\title{
Natural and Socioeconomic Factors and Their Interactive Effects on House Collapse Caused by Typhoon Mangkhut
}

\author{
Xiangxue Zhang ${ }^{1,2} \cdot$ Juan Nie $^{3} \cdot$ Changxiu Cheng ${ }^{1,4,5} \cdot$ Chengdong $\mathrm{Xu}^{2}$. \\ Ling Zhou ${ }^{2} \cdot$ Shi Shen ${ }^{1,4} \cdot$ Yuan $\mathrm{Pei}^{3}$
}

Accepted: 2 November 2020/Published online: 24 November 2020

(C) The Author(s) 2020

\begin{abstract}
Typhoons are an environmental threat that mainly affects coastal regions worldwide. The interactive effects of natural and socioeconomic factors on the losses caused by typhoon disasters need further examination. In this study, GeoDetector was used to quantify the determinant powers of natural and socioeconomic factors and their interactive effects on the rate of house collapse in Guangdong and Guangxi Provinces of southeast China caused by Typhoon Mangkhut in 2018. We further identify the dominant factors that influenced the disaster losses. The local indicators of spatial association method was then introduced to explain the spatial heterogeneity of the disaster losses under the influence of the dominant factor. The results indicate that both natural and socioeconomic factors significantly affected the house collapse rate. The maximum precipitation was the dominant factor, with a $q$ value of 0.21 , followed by slope and elevation, with $q$ values
\end{abstract}

Changxiu Cheng

chengcx@bnu.edu.cn

$\triangle$ Chengdong Xu

xucd@1reis.ac.cn

1 Key Laboratory of Environmental Change and Natural Disaster, Ministry of Education, Beijing Normal University, Beijing 100875, China

2 State Key Laboratory of Resources and Environmental Information System, Institute of Geographic Sciences and Natural Resources Research, Chinese Academy of Sciences, Beijing 100101, China

3 National Disaster Reduction Center of China, Ministry of Emergency Management, Beijing 100124, China

4 State Key Laboratory of Earth Surface Processes and Resource Ecology, Beijing Normal University, Beijing 100875, China

5 National Tibetan Plateau Data Center, Beijing 100101, China of 0.17 and 0.13 , respectively. Population density and per capita gross domestic product had $q$ values of 0.15 and 0.13 , respectively. Among all of the interactive effects of the influencing factors, the interactive effect of elevation and the ratio of brick-wood houses had the greatest influence $(q=0.63)$ on the house collapse rate. These results can contribute to the formulation of more specific safety and property protection policies.

Keywords China - Coastal regions - GeoDetector . House collapse rate $\cdot$ Interactive effects · Typhoon Mangkhut

\section{Introduction}

Typhoons are one of the most frequent and severe natural hazards that occur worldwide (Peduzzi et al. 2012; Mei et al. 2015). They not only cause losses of life and property, but also have major socioeconomic effects on coastal areas (Lin et al. 2015; Yan et al. 2016). China experiences great damage from typhoons, and economic development and the lives of over 250 million people have been severely affected (Liu et al. 2009; Xu et al. 2013). The issue of public safety in the context of increasing typhoon risks is attracting increasing attention.

The eastern coastal area of China is a sensitive ecological environment, and frequently experiences climatic anomalies and catastrophic natural phenomena caused by global warming and rising sea levels (Huang and Cheng 2013; Xu et al. 2016). Climate change and sea level rise can cause various sudden and complex natural hazards that further exacerbate the intensity and frequency of natural hazards in coastal areas undergoing rapid urbanization. The vulnerability and disaster risks of coastal cities are 
increasing (Huang and Cheng 2013). Studies have demonstrated that the coastal areas of China-including the Yellow River Delta, the Yangtze River Delta, and the Pearl River Delta - are at the greatest risk of rising sea levels and land subsidence. These areas will continue to face extreme threats due to typhoons, storm surges, floods, and other natural hazards in the future (Syvitski et al. 2009). With the rapid expansion of the population and economic development, concomitant disasters will continue to increase, the original hazard factors will continue to expand and change, new hazards and disasters will be constantly generated, and the effects of disasters will become more significant (Knutson et al. 2010; Li et al. 2018).

Multidisciplinary studies have been conducted on the causes and driving factors of typhoons. Most previous studies reported that the risk of typhoon disasters is not only closely related to parameters such as wind speed, changes in ocean temperature, the El Niño-Southern Oscillation, and tropical cyclones (Elsner and Liu 2003; Mei et al. 2015; Mei and Xie 2016), but also to the vulnerability of the hazard-affected elements and the capacity of the disaster prevention and mitigation systems. With the rapid growth of urbanization, socioeconomic activities will affect these causes. Since the 1980s, research on typhoon disasters has increasingly focused on safety improvement with respect to the economy and society, and has attached great importance to the vulnerability of human economic, social, and cultural systems to natural hazard-induced disasters (Vrijling et al. 1995; Nigusse and Adhanom 2019). This has since become a multiscale, comprehensive concept influenced by nature, society, the economy, and the environment (Cheung 2007). In recent years, the association between disaster losses caused by typhoons and the socioeconomic conditions has attracted great attention from researchers in multidisciplinary fields, such as economics, urbanization, construction, and demographics (Vrijling et al. 1995; Nigusse and Adhanom 2019).

The disaster losses caused by typhoons are affected by natural and socioeconomic factors. However, most previous studies mainly focused on analyzing the effect of unilateral factors separately, such as natural or socioeconomic factors, while the effects of integrated natural and socioeconomic factors on the house collapse rate due to typhoons, for example, have rarely been examined. Additionally, traditional statistical methods are unable to detect the interactive effects of factors that influence disaster losses. In reality, the interactive effects of two factors can occur in multiple coupling forms; however, the results of traditional regression methods are typically the product of two factors (Pearce et al. 2011; Yang et al. 2018). Machine learning algorithms or regression methods have been used to calculate the coefficients with spatial differences; however, they have poor capacity to resolve problems when the data have spatially stratified heterogeneity (Wang et al. 2010; Lin et al. 2014; Wang et al. 2016; Wang and Xu 2017).

The southeastern coastal areas of China are undergoing tremendous economic growth and are home to an increasingly important city cluster, such as Shanghai, Shenzhen, and Guangzhou, due to rapid urbanization and industrialization. It is also one of the main regions facing severe natural hazards and disasters, particularly related to typhoons. Therefore, quantifying the determinant powers of potential factors and their interactive effects is important for successful policy making to control and reduce casualties and property damages. This study aimed to (1) quantitatively investigate the determinants of natural and socioeconomic factors and their interactive effects on the house collapse rate due to 2018 Typhoon Mangkhut by GeoDetector; and (2) reveal the spatial heterogeneity of the house collapse rate under the effect of the dominant factor using the local indicators of spatial association (LISA) method. This work can facilitate the formulation of more scientific and specific safety and property protection policies.

\section{Methods}

The content of the section is organized as follows. Section 2.1 introduces the study area. Section 2.2 introduces the typhoon data. Section 2.3 provides the data sources of potential driving factors. Section 2.4 describes the methodology.

\subsection{Study Area}

The coastal regions of southeastern China are more economically developed, densely populated, and frequently hit by extreme weather-such as strong winds and heavy precipitation due to typhoons, which often cause loss of life and property-than other regions in China (Zhang et al. 2011a). This is particularly evident in Guangdong and Guangxi Provinces (Zhang et al. 2011b; Tian et al. 2016). A total of 147 counties in these two provinces were most severely affected by 2018 Typhoon Mangkhut, one of the most destructive typhoons in the past decade (Liu et al. 2020). Thus, these two provinces were chosen as the study area (Fig. 1). Guangdong is one of the economic centers of China. The area of the case study provinces is $416,400 \mathrm{~km}^{2}$, with a population of approximately 165 million. In recent years, the accelerated urbanization and industrialization in this region have exacerbated disaster losses. Therefore, rapid emergency response measures for major disasters in this region must be developed. 


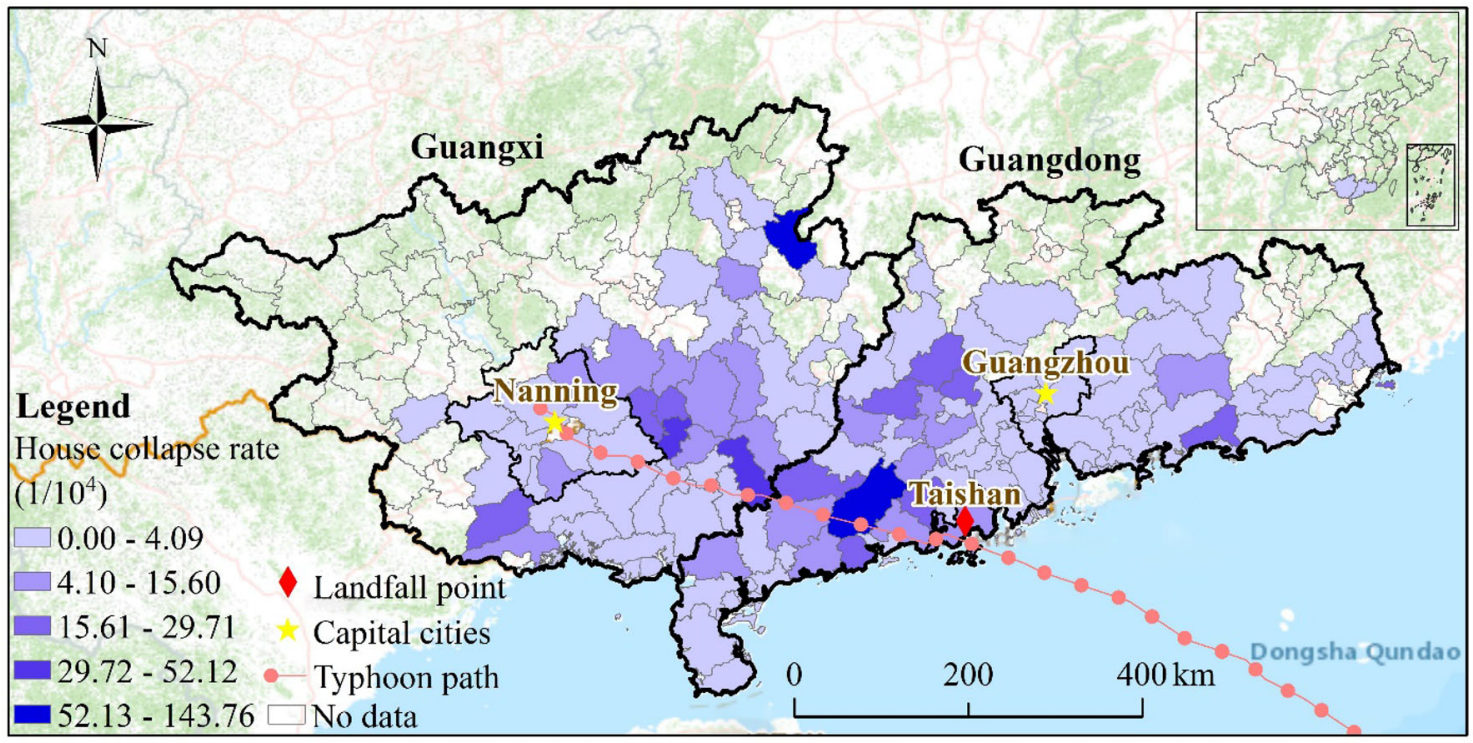

Fig. 1 Geographical location of Guangdong and Guangxi Provinces in China, and the rate of house collapse caused by 2018 Typhoon Mangkhut. Source: https://data.cnki.net

\subsection{Typhoon Mangkhut Data}

At 17:00 on 13 September, 2018, Typhoon Mangkhut made landfall in Taishan City of Guangdong Province, China, with 14-level high wind intensity. After landfall, the typhoon continued to move northwest, causing severe damage, particularly in Guangdong and Guangxi Provinces. Due to its high intensity, it caused storm surges and heavy rainfall that affected over 4.71 million people, caused over 3400 houses to collapse, and damaged 11,000 houses to varying degrees. Over 341.4 thousand hectares of crops were affected, and the direct economic losses reached USD 2.07 billion. The typhoon hazard data were collected from the China Meteorological Administration. ${ }^{1}$ Error! Hyperlink reference not valid. Data regarding the rate of house collapse due to Mangkhut in Guangdong and Guangxi were used to explore the driving factors and analyze the spatial characteristics of the disaster, and were collected from the Yearbook of Meteorological Disasters in China $^{2}$ and Guangdong/Guangxi governmental economic statistical yearbooks ${ }^{3}$ (Fig. 1).

\subsection{Potential Driving Factors of House Collapse and Proxies}

Based on a comprehensive consideration of the hazard, the environment, the vulnerability of the affected communities,

\footnotetext{
${ }^{1}$ http://2011.cma.gov.cn.

2 https://data.cnki.net/statisticalData.

${ }^{3}$ https://data.cnki.net.
}

the disaster prevention and reduction capacity (Shi et al. 2020), the results of previous studies (Gong and $\mathrm{Hu} 2015$; $\mathrm{Hu}$ et al. 2018; Nigusse and Adhanom 2019; Yuan et al. 2020), and the availability of data, the 2018 house structures for each county of the study area that is the ratio of steel-concrete houses (RS), the ratio of brick-concrete houses (RC), and the ratio of brick-wood houses (RB) were taken as the explanatory variables. The variables of the socioeconomic factors for each county included the population density (PD), per capita GDP (PG), the ratio of urban to rural population (UR), high school penetration rate (HS), per capita housing area (PA), and the proportion of the tertiary industry (PT). The natural environment and hazard factors included the daily maximum precipitation (MP), slope (SP), elevation (EV), and typhoon level (TY, wind speed caused by the typhoon) (Table 1). The mean daily MP for 2018, SP, and EV data for each county of the study area were extracted using the regional statistical tools in ArcGIS 10.3.

\subsection{Statistical Analysis}

GeoDetector was used to quantify the determinant power of the natural and socioeconomic factors, further explain the dominant factor, and quantify the interactive effects of the natural and socioeconomic factors on the house collapse rate due to Typhoon Mangkhut. This information can be used to fill the knowledge gap. The LISA model was then used to reveal the spatial heterogeneity of the house collapse rate under the influence of the dominant factor and classify the study area in terms of hot (High-High; high- 
Table 1 Description of the explanatory variables and data sources used for the study area

\begin{tabular}{|c|c|c|c|}
\hline Variable & Definition & Unit & Data sources \\
\hline \multirow[t]{2}{*}{ Hazard (A) } & Maximum precipitation (MP) & $\mathrm{mm}$ & $\begin{array}{l}\text { Resource and Environment Data Cloud } \\
\text { Platform (http://www.resdc.cn); resolution: } \\
1 \mathrm{~km} \times 1 \mathrm{~km}\end{array}$ \\
\hline & Typhoon level (TY) & level & $\begin{array}{l}\text { China Meteorological Administration (http:// } \\
\text { 2011.cma.gov.cn) and the disaster area } \\
\text { statistics }\end{array}$ \\
\hline \multirow[t]{2}{*}{ Environmental factors (B) } & Slope (SP) & $\%$ & \multirow{2}{*}{$\begin{array}{l}\text { Resource and Environment Data Cloud } \\
\text { Platform (http://www.resdc.cn); resolution: } \\
1 \mathrm{~km} \times 1 \mathrm{~km}\end{array}$} \\
\hline & Elevation (EV) & $\mathrm{m}$ & \\
\hline \multirow{6}{*}{$\begin{array}{l}\text { Vulnerability of hazard- } \\
\text { affected bodies (C) }\end{array}$} & Ratio of steel-concrete houses (RS) & $\%$ & \multirow{6}{*}{$\begin{array}{l}\text { Yearbook of Meteorological Disasters in } \\
\text { China and Guangdong/Guangxi } \\
\text { governmental economic statistical } \\
\text { yearbook (http://data.cnki.net) }\end{array}$} \\
\hline & Ratio of brick-concrete houses (RC) & $\%$ & \\
\hline & Ratio of brick-wood houses (RB) & $\%$ & \\
\hline & Population density (PD) & person $/ \mathrm{km}^{2}$ & \\
\hline & Per capita housing area (PA) & $\mathrm{m}^{2} /$ person & \\
\hline & Ratio of urban to rural population (UR) & l & \\
\hline \multirow{3}{*}{$\begin{array}{l}\text { Capacity of disaster prevention } \\
\text { and reduction (D) }\end{array}$} & Per capita GDP (PG) & $\mathrm{CNY}$ & \multirow{3}{*}{$\begin{array}{l}\text { Guangdong/Guangxi governmental economic } \\
\text { statistical yearbook (http://data.cnki.net) }\end{array}$} \\
\hline & High school penetration rate (HS) & $\%$ & \\
\hline & Proportion of the tertiary industry (PT) & $\%$ & \\
\hline
\end{tabular}

risk areas) and cold (Low-Low; low-risk areas) spots affected by Typhoon Mangkhut.

\subsubsection{GeoDetector}

The GeoDetector method can effectively consider conditions with spatial heterogeneity, and it is assumed that if the potential impact variable affects the response variable, the response variable will exhibit a spatial distribution similar to that of the impact variable (Wang et al. 2010; Wang et al. 2016; Wang and Xu 2017). GeoDetector can quantify the determinant power of a single factor as an independent variable, and can also estimate the interactive effects of different factors, which is more comprehensive and informative than traditional methods in explaining geographical phenomena. GeoDetector was used to quantify the determinant powers of single or different interacting factors on the response variable (house collapse rate), and can be defined as follows:

$q=1-\frac{1}{N \sigma^{2}} \sum_{h=1}^{L} N_{h} \sigma_{h}^{2}$

where $q$ quantifies the determinant powers of single or interactive factors, ranging from 0 to $1 ; h(h=1,2, \ldots$, $L$ ) represents the spatial stratification of a single factor $X$, or the crossed strata of multifactor $X$ values; $N$ and $N_{h}$ are the number of counties in the entire area and strata $h$, respectively; and $\sigma^{2}$ and $\sigma_{h}^{2}$ indicate the variations in the entire area or stratum $h$, respectively.

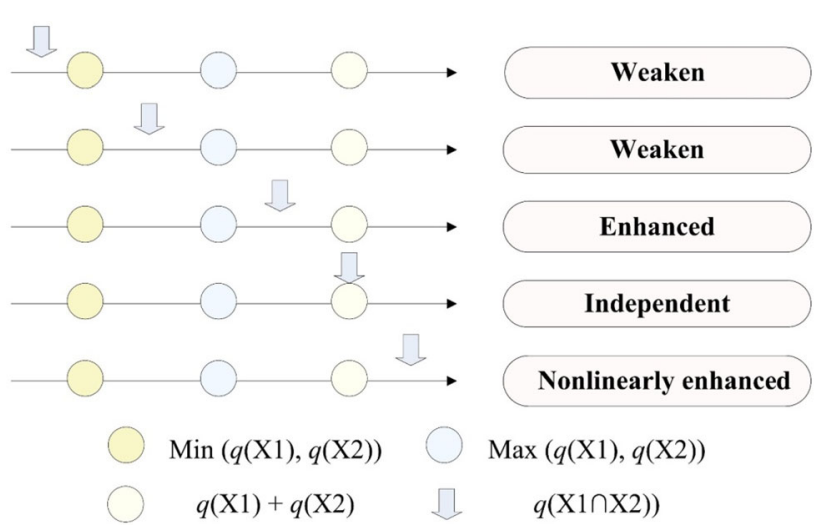

Fig. 2 The interactive categories of two factors and the interactive relationship

The interactive effects of factors $(X s)$ can also be quantified using GeoDetector, which can further reveal whether the interactive effects of different factors $(X 1 \cap X 2)$ weaken or enhance the influence on the response variable; $q(X 1), q(X 2)$, and $q(X 1 \cap X 2)$ represent the $q$ values of $X 1$ and $X 2$, and interactive effects of $X 1$ and $X 2(X 1 \cap X 2)$, respectively. The interactive effects of different factors can be classified into five categories by comparing $q(X 1)$, $q(X 2)$, and $q(X 1 \cap X 2)$ (Wang et al. 2010; Wang et al. 2016; Wang and Xu 2017). In Fig. 2, the top row indicates univariate weaken; the second row indicates univariate weaken; the third row indicates bivariate enhance; the fourth row indicates independent; and the fifth row indicates nonlinearly enhance of interactive relationship. Moreover, significance of the $q$-statistic value was 
determined by the $F$ test with a significance level of 0.05 . All processes implemented above were calculated using GeoDetector. ${ }^{4}$

\subsubsection{Spatial Pattern Identification}

To further measure the local spatial associations and identify the types of spatial correlation between the response variable (house collapse rate) and the dominant impact factors detected by the GeoDetector method (Boots and Tiefelsdorf 2000; Huo et al. 2012), the local indicators of spatial association (LISA) method was used as follows:

$I_{m l}^{i}=Z_{m}^{i} \sum_{j=1}^{n} W_{i j} Z_{l}^{i}$

$Z_{m}^{i}=\frac{x_{m}^{i}-\bar{x}_{m}}{\sigma_{m}}, \quad Z_{l}^{i}=\frac{x_{l}^{j}-\overline{x_{l}}}{\sigma_{l}}$

where $x_{m}^{i}$ and $x_{l}^{j}$ are observations $m$ and $l$ at locations $i$ and $j$, respectively, with average values of $\bar{x}_{m}$ and $\bar{x}_{l}$, respectively; $\sigma_{m}$ and $\sigma_{l}$ are the variances of $x_{m}$ and $x_{l}$, respectively; and $W_{i j}$ is a spatially adjacent matrix.

$Z_{m}^{i}$ and the corresponding spatial lag $W Z_{l}^{i}$ at location $i$ were mapped on the vertical and horizontal axes of Moran's I scatter plot, respectively. The spatial correlation was divided into four quadrants by the coordinate axis, with the first and third quadrants indicating a positive spatial correlation, and the second and fourth quadrants representing a negative spatial correlation, allowing us to observe spatial clusters-that is, hot (High-High) or cold (Low-Low) spots. Conversely, if a negative correlation was observed, spatial outliers were present (that is, HighLow or Low-High areas). All of the above processes were conducted in GeoData (Anselin et al. 2006).

\section{Results}

The content of the section is organized as follows. Section 3.1 describes the results of GeoDetector. Section 3.2 introduces the spatial clusters of house collapse rate caused by Typhoon Mangkhut.

\subsection{GeoDetector Statistical Results}

GeoDetector was used to quantify the determinant powers ( $q$-values) of single natural and socioeconomic factors and their interactive effects on the house collapse rate due to 2018 Typhoon Mangkhut, and the results are shown in Fig. 3. Among the selected influencing factors, MP was the dominant factor with the greatest impact on the

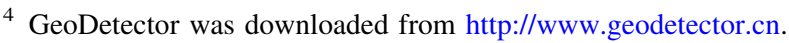

heterogeneity of the house collapse rate $(q=0.21)$, followed by $\mathrm{SP}(q=0.17), \mathrm{PD}(q=0.15), \mathrm{EV}(q=0.13)$, and PG ( $q=$ $0.13)$, while TY had the lowest influence $(q=0.01)$. Therefore, both natural and socioeconomic factors significantly impacted the house collapse rate. The $q$ values of RC, RB and RS were $0.12,0.11$ and 0.08 , respectively, indicating that the house structures significantly impacted the house collapse rate. The $q$ values of PA and UR were 0.09 and 0.05 , respectively, indicating that the socioeconomic conditions also significantly impacted the house collapse rate, along with PT and HS ( $q=0.08$ and 0.07 , respectively).

The interactive determinant powers of 78 pairs of any two of the 13 influencing factors were determined using GeoDetector. The determinant powers of the interactive effects of each pair of natural and socioeconomic factors on the house collapse rate were much greater than those of their individual effects. Therefore, the house collapse rate was not affected by a single factor, but was largely influenced by the interactive effects of factors (Fig. 4). Among all the interactive effects of any two factors, the maximum is 0.63 ( $\mathrm{EV}$ and $\mathrm{RB}$ ), indicating that the interactive effects of $\mathrm{EV}$ and $\mathrm{RB}$ on the house collapse rate were the strongest, followed by MP and PD, and MP and EV, with $q$ values of 0.61 and 0.60 , respectively, indicating that strong precipitation combined with other influencing factors significantly affected the house collapse rate. These results suggest that the interactive effects of two factors will strengthen the impact on house collapse.

\subsection{Spatial Clusters}

The overall spatial autocorrelation and spatial pattern of the house collapse rate due to Typhoon Mangkhut were examined by conducting Moran's $I$ test considering the effect of a dominant factor (maximum precipitation), and hot/cold spots where the house collapse risk was high/low were then identified. The global Moran's $I$ index of the house collapse rate was 0.09 , and the $p$ value was 0.04 , indicating that the house collapse rate had a statistically significant, weak spatial positive autocorrelation. The local spatial autocorrelation variations were analyzed through LISA verification, and hot spots (High-High areas) and cold spots (Low-Low areas) were identified. Hot spots represent the areas where the house collapse rate was high; thus, they were considered as high-risk areas for house collapse due to Typhoon Mangkhut. Cold spots represent areas where the house collapse rate was low; thus, they were considered as low-risk areas. Hot spots were mainly located in southwestern Guangdong (Fig. 5), indicating that these regions experienced severe house collapse. Cold spots were mainly located in northeastern and southern Guangxi, indicating that these regions experienced less house collapse. 
Fig. 3 The influences of factors in driving house collapse. $M P$ daily maximum precipitation, $T Y$ Typhoon level, $S P$ slope, $E V$ elevation, $R S$ steel-concrete houses, $R C$ ratio of brickconcrete houses, $R B$ ratio of brick-wood houses, $P D$ population density, $P A$ per capita housing area, $U R$ ratio of urban to rural population, $P G$ per capita GDP, $H S$ high school penetration rate, $P T$ proportion of the tertiary industry

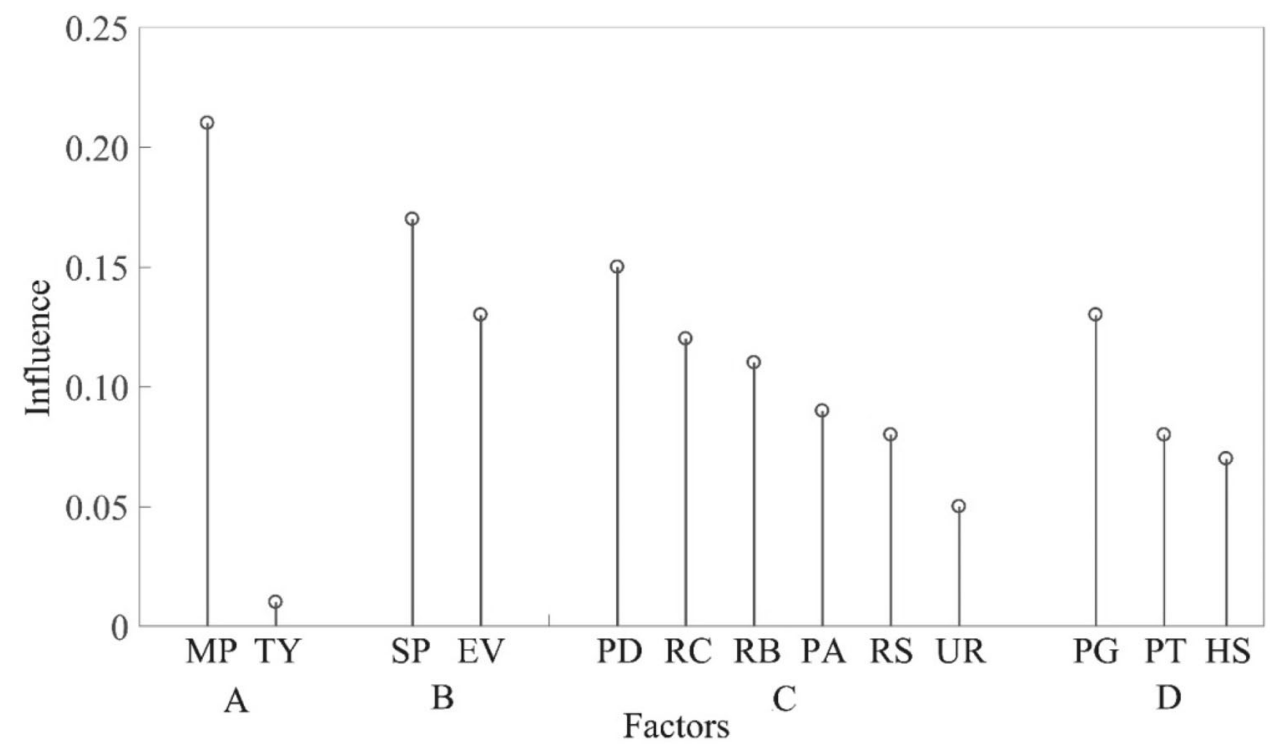

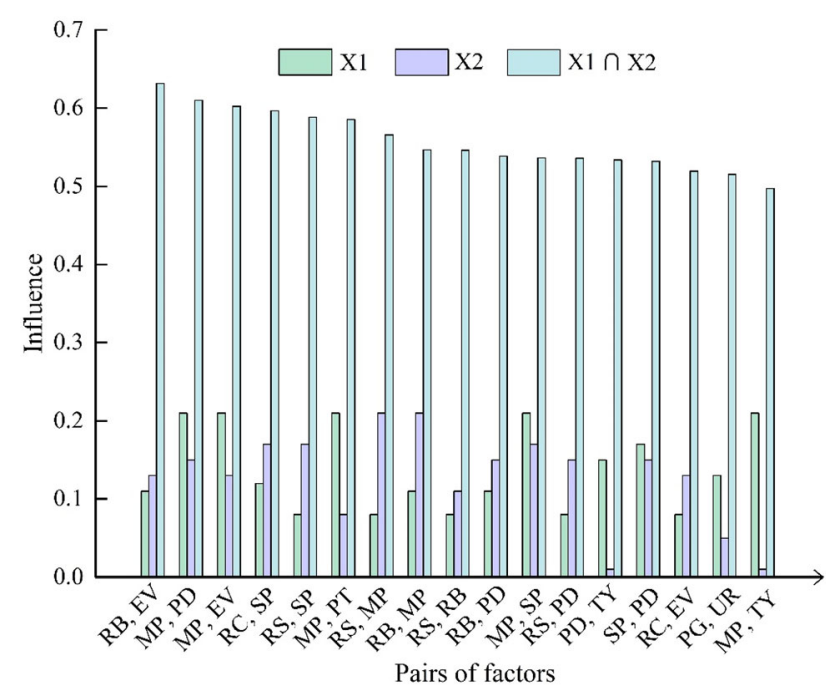

Fig. 4 The interaction effects of factors on house collapse. $M P$ daily maximum precipitation, $T Y$ Typhoon level, $S P$ slope, $E V$ elevation, $R S$ steel-concrete houses, $R C$ ratio of brick-concrete houses, $R B$ ratio of brick-wood houses, $P D$ population density, $P A$ per capita housing area, $U R$ ratio of urban to rural population, $P G$ per capita GDP, $H S$ high school penetration rate, $P T$ proportion of the tertiary industry. Note $X 1$ represents the first factor, $X 2$ denotes the second factor, and $X 1$ and $X 2$ represent the interactive effects of the two factors, where the $q$ value of the interactive effect exceeds 0.50

\section{Discussion}

Considering the hazard, sensitivity of the environment, the vulnerability of hazard-affected elements, and the capacity for comprehensive disaster prevention and reduction as possible factors (Shen et al. 2009; Di Baldassarre et al. 2010; Hu et al. 2018; Shi et al. 2020), the determinant powers and interactive effects of the natural and socioeconomic factors on the house collapse rate due to Typhoon
Mangkhut were quantified using GeoDetector. The heterogeneous spatial pattern of the house collapse rate under the effect of a dominant factor (maximum precipitation) was then examined, and hot and cold spots were identified through the LISA model. The results show that both natural and socioeconomic factors significantly impacted the house collapse rate, including MP, SP, EV, $\mathrm{PD}$, and PG. Among all of the interactive effects of influencing factors, the interactive effect between EV and RB was the strongest $(q=0.63)$. Hot spots of the house collapse rate were mainly distributed in southwestern Guangdong, which suffered more severe precipitation caused by Typhoon Mangkhut than the other counties of the study area, and cold spots were mainly located in northeastern and southern Guangxi, where precipitation caused by Typhoon Mangkhut was less than other counties of the study area.

Heavy precipitation caused by typhoons greatly threatens the safety of people and property (Jongman et al. 2012; Lin et al. 2015; Yan et al. 2016; Hu et al. 2018). The determinant power of MP on the house collapse rate was the strongest $(q=0.21)$, which is consistent with the findings of previous studies. Hu et al. (2018) and Jongman et al. (2012) reported that extreme precipitation can cause flood disasters and affect the persistently increasing exposure of population and assets. Lin et al. (2015) and Yan et al. (2016) demonstrated that heavy precipitation and floods caused by tropical cyclones have caused great population and economic losses worldwide. These studies suggest that heavy precipitation is a key indicator of typhoon energy release and among the main disastercausing factors. The interactive effects of MP and other factors, such as PD and EV, had a stronger impact on the house collapse rate due to Typhoon Mangkhut, indicating 


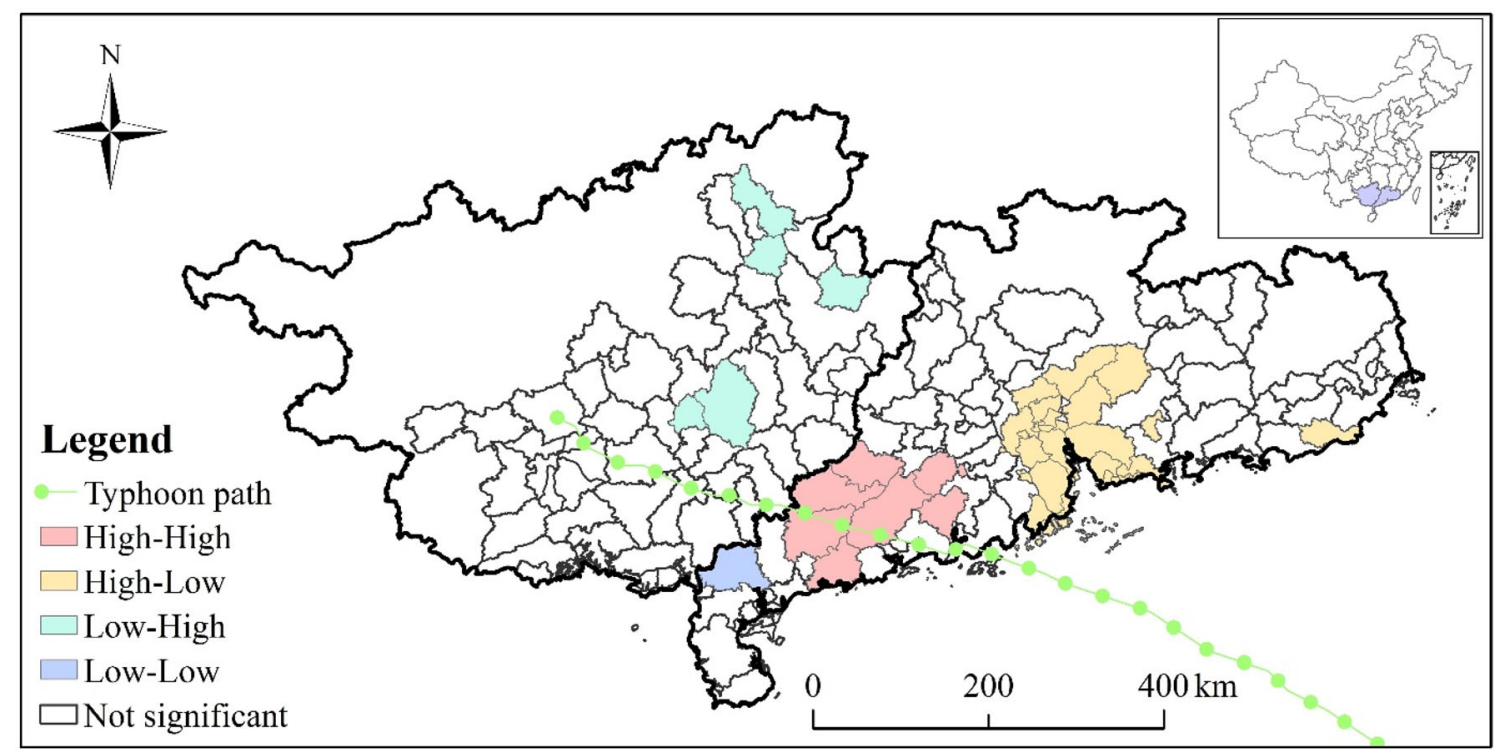

Fig. 5 Spatial distribution of the local indicators of spatial association (LISA) for the house collapse rate under the effect of maximum precipitation in Guangdong and Guangxi Provinces caused by Typhoon Mangkhut in 2018

that heavy precipitation will not only have a great impact on the house collapse rate, but greatly increases the impact of other factors on the house collapse rate. This may be because heavy precipitation causes secondary disasters, such as floods and mudslides, that lead to great disasters in coastal areas (Khouakhi et al. 2017), and threaten the safety of people and property. Areas with developed economies and dense populations are highly sensitive to disasters, such as floods, rainstorms, and rising water levels. Hence, the interactive effects of precipitation and socioeconomic factors can strengthen the magnitude and intensity of typhoon disasters in this region (Zhang et al. 2008; Zhang et al. 2012; Yang et al. 2015).

Slope (SP) was another significant factor associated with the house collapse rate, with a determinant power of 0.17 , and exerted a notable effect on the house collapse rate that was comparable to the results of some previous studies (Smyth and Royle 2000; Fernandez and Lutz 2010). Nigusse and Adhanom (2019) reported that, in areas with flat slopes and lower elevations, more people and buildings are the most vulnerable to flooding. Smyth and Royle (2000) demonstrated that slope has an important effect on house damage. The interactive effects between SP and other factors, such as RC and RS, exerted a stronger impact on the house collapse rate due to Typhoon Mangkhut, indicating that the combination of the slope with house structures increases the impact on the house collapse rate. The underlying mechanism may be the heavy torrential precipitation and the resulting flood during typhoons, as the water flow damages the structures or components of houses and results in collapses.
Coastal areas with elevations of less than $5 \mathrm{~m}$ above sea level are more vulnerable to sea level rises and storm surges (Atanas and Hristo 2009). The coastal areas of China below $5 \mathrm{~m}$ cover an area of approximately 143.9 thousand $\mathrm{km}^{2}$, mainly distributed along the southeast coastal region (Huang and Cheng 2013). We observed a strong relationship between EV and house collapse rate, with a determinant power of 0.13 , indicating that EV has a significant impact on the house collapse rate, which is consistent with the findings of previous studies. Huang and Cheng (2013) reported that, when hit by a typhoon, the collapse of a house is affected by the local elevation. Nigusse and Adhanom (2019) demonstrated that elevation is one of the most important parameters when typhoons hit. Yuan et al. (2020) also demonstrated that elevation was the most influential factor when a typhoon arrives. The interactive effects between EV and other factors, such as MP and RS, were strong on the house collapse rate due to Typhoon Mangkhut, with the determinant powers of 0.60 and 0.52 , respectively, indicating that the combination of $\mathrm{EV}$ with precipitation and house structures increases the impact of typhoons on the house collapse rate. The underlying mechanism for the effects of elevation on the house collapse rate may be the lower susceptibility to flooding or storm surges due to typhoons at higher elevation (Atanas and Hristo 2009; Huang and Cheng 2013). When a typhoon arrives, areas with lower elevation will experience a higher house collapse rate. Guangxi experiences the opposite situation in areas with higher elevation, with relatively high house collapse rates, which may be related to the poor local economic conditions, such as a higher brick-wood house ratio. 
In addition to natural factors, socioeconomic factors had important impacts on house damage due to Typhoon Mangkhut. For example, the determinant power of PD was 0.15 , indicating that PD had a significant impact on the house collapse rate, which was comparable to the results reported in previous studies. Ying et al. (2011) reported that PD has a significant impact on disaster loss due to typhoons. Similarly, $\mathrm{Hu}$ et al. (2018) demonstrated that high PD, as a vulnerability factor of hazard affected communities, is closely related to flood disasters caused by typhoons and increases the effect of typhoons on the safety of people and property. Nigusse and Adhanom (2019) also noted that PD had an important effect on the response to flood hazards. The underlying mechanism may be rapid urbanization, which promotes economic growth and population agglomeration, and various types of infrastructure continue to be constructed to meet people's various needs. That is, typhoon disasters are further enhanced by increasing population density as the roads and buildings are more concentrated. Moreover, due to the large number of migrant workers in the coastal areas whose education level and knowledge regarding disaster prevention and reduction are limited, the disaster effect will intensify (Brown et al. 2013).

The interactive effects between natural and socioeconomic factors were all enhanced from the effects of single factors, as revealed by the GeoDetector analysis. Socioeconomic factors have been closely related to anthropogenic activities over the past decades, and the original ecological environment and living conditions have undergone great changes with the rapidly increasing global urbanization (Gong et al. 2012). Therefore, the interactive effects between socioeconomic and natural factors will amplify the effects of disasters to some extent, and reinforce one another in influencing the collapse of houses.

Hot and cold spots of the house collapse rate were revealed by LISA. Hot spots were mainly located in southwestern Guangdong, indicating that these regions experienced significantly severe house collapse. Cold spots were mainly located in the northeastern and southern regions of Guangxi, indicating that these regions experienced a significantly lower house collapse rate than other counties of the study area. These results indicated that, in addition to natural factors, the socioeconomic development level also has a certain intervention effect on the outcome of disasters, which is consistent with the results of previous research. Zhang et al. (2017) reported that heavy precipitation caused by typhoons resulted in a decrease in population mortality with the growth of PG. Hu et al. (2018) reported that there was a negative association between $\mathrm{PG}$ and the flood deaths caused by a typhoon. The underlying mechanism may be the great improvements in disaster prevention infrastructure and the ability to mitigate disasters with socioeconomic development.

This study has some limitations. The first is that the typhoon disaster system is a complex subsystem of the Earth system, which is affected by various complex natural processes and human activities. This study only considered some natural, demographic, and socioeconomic factors as the influencing factors for the house collapse rate, while several environmental factors, such as air temperature and humidity, were omitted. The second limitation is that the spatial scale used in this study was the county level, which may obscure some factors through the ecological fallacy effect and could introduce some uncertainties.

\section{Conclusion}

In this study, the influences of natural and socioeconomic factors on the rate of house collapse caused by Typhoon Mangkhut in Guangdong and Guangxi Provinces were quantified by GeoDetector, along with their interactions. Moreover, the spatial heterogeneity of the house collapse rate was revealed by LISA. The results indicate that both natural and socioeconomic factors can influence the impacts of disasters, further demonstrating that the spatial heterogeneity of the house collapse rate is related to the spatial differentiation of these influencing factors and their interactive effects. These findings can aid in the development of specific strategies for damage prevention and control, and the allocation of resources for different regions to enhance their disaster response capacity and reduce potential losses.

Acknowledgements This study was financially supported by the following Grants: National Key Research and Development Plan of China (2019YFA0606901; 2017YFC1503002).

Open Access This article is licensed under a Creative Commons Attribution 4.0 International License, which permits use, sharing, adaptation, distribution and reproduction in any medium or format, as long as you give appropriate credit to the original author(s) and the source, provide a link to the Creative Commons licence, and indicate if changes were made. The images or other third party material in this article are included in the article's Creative Commons licence, unless indicated otherwise in a credit line to the material. If material is not included in the article's Creative Commons licence and your intended use is not permitted by statutory regulation or exceeds the permitted use, you will need to obtain permission directly from the copyright holder. To view a copy of this licence, visit http://creativecommons. org/licenses/by/4.0/.

\section{References}

Anselin, L., I. Syabri, and Y. Kho. 2006. GeoDa: An introduction to spatial data analysis. Geographical Analysis 38(1): 5-22. 
Atanas, P., and S. Hristo. 2009. Risk for the population along the Bulgarian black seacoast from flooding caused by extreme rise of sea level. Information \& Security: An International Journal 24: $65-75$.

Boots, B., and M. Tiefelsdorf. 2000. Global and local spatial autocorrelation in bounded regular tessellations. Journal of Geographical Systems 2(4): 319-348.

Brown, R.C., S.K. Trapp, E.C. Berenz, T.B. Bigdeli, R. Acierno, T. Trinh Luong, L.T. Trung, N.T. Tam, et al. 2013. Pre-typhoon socioeconomic status factors predict post-typhoon psychiatric symptoms in a Vietnamese sample. Social Psychiatry and Psychiatric Epidemiology 48(11): 1721-1727.

Cheung, N.K.W. 2007. At risk: Natural hazards, people's vulnerability and disasters. Geographical Journal 173(2): 189-190.

Di Baldassarre, G., A. Montanari, H. Lins, D. Koutsoyiannis, L. Brandimarte, and G. Bloeschl. 2010. Flood fatalities in Africa: From diagnosis to mitigation. Geophysical Research Letters 37(22): Article L22402.

Elsner, J.B., and K.B. Liu. 2003. Examining the ENSO-typhoon hypothesis. Climate Research 25(1): 43-54.

Fernandez, D.S., and M.A. Lutz. 2010. Urban flood hazard zoning in Tucuman Province, Argentina, using GIS and multicriteria decision analysis. Engineering Geology 111(1-4): 90-98.

Gong, P., S. Liang, E.J. Carlton, Q. Jiang, J. Wu, L. Wang, and J.V. Remais. 2012. Urbanisation and health in China. Lancet 379(9818): 843-852.

Gong, Z., and L. Hu. 2015. Influence factor analysis of typhoon disaster assessment. Journal of Natural Disasters 24(1): 203-213.

Hu, P., Q. Zhang, P. Shi, B. Chen, and J. Fang. 2018. Flood-induced mortality across the globe: Spatiotemporal pattern and influencing factors. Science of the Total Environment 643: 171-182.

Huang, Y., and H. Cheng. 2013. The impact of climate change on coastal geological disasters in southeastern China. Natural Hazards 65(1): 377-390.

Huo, X.N., H. Li, D.F. Sun, L.D. Zhou, and B.G. Li. 2012. Combining geostatistics with Moran's I analysis for mapping soil heavy metals in Beijing, China. International Journal of Environmental Research and Public Health 9(3): 995-1017.

Jongman, B., P.J. Ward, and J.C.J.H. Aerts. 2012. Global exposure to river and coastal flooding: Long term trends and changes. Global Environmental Change - Human and Policy Dimensions 22(4): 823-835.

Khouakhi, A., G. Villarini, and G.A. Vecchi. 2017. Contribution of tropical cyclones to rainfall at the global scale. Journal of Climate 30(1): 359-372.

Knutson, T.R., J.L. McBride, J. Chan, K. Emanuel, G. Holland, C. Landsea, I. Held, J.P. Kossin, et al. 2010. Tropical cyclones and climate change. Nature Geoscience 3(3): 157-163.

Li, E., Y. Huang, H. Chen, and J. Zhang. 2018. Floristic diversity analysis of the Ordos Plateau, a biodiversity hotspot in arid and semi-arid areas of China. Folia Geobotanica 53(4): 405-416.

Lin, G., J. Fu, D. Jiang, W. Hu, D. Dong, Y. Huang, and M. Zhao. 2014. Spatio-temporal variation of $\mathrm{PM}_{2.5}$ concentrations and their relationship with geographic and socioeconomic factors in China. International Journal of Environmental Research and Public Health 11(1): 173-186.

Lin, Y., M. Zhao, and M. Zhang. 2015. Tropical cyclone rainfall area controlled by relative sea surface temperature. Nature Coтmunications 6: Article 6951.

Liu, D., L. Pang, and B. Xie. 2009. Typhoon disaster in China: prediction, prevention, and mitigation. Natural Hazards 49(3): 421-436.

Liu, X., Q. Wang, C. Liu, Y. He, S. Wang, P. Hou, X. Zhu, and Z. Wu. 2020. Wind field reconstruction and analysis of Super
Typhoon Mangkhut (1822). Journal of Coastal Research 99(SI): 151-157.

Mei, W., and S.P. Xie. 2016. Intensification of landfalling typhoons over the northwest Pacific since the late 1970 s. Nature Geoscience 9(10): Article 753.

Mei, W., S.P. Xie, F. Primeau, J.C. McWilliams, and C. Pasquero. 2015. Northwestern Pacific typhoon intensity controlled by changes in ocean temperatures. Science Advances 1: Article e1500014.

Nigusse, A.G., and O.G. Adhanom. 2019. Flood hazard and flood risk vulnerability mapping using geo-spatial and MCDA around Adigrat, Tigray region, Northern Ethiopia. Momona Ethiopian Journal of Science 11(1): 90-107.

Pearce, J.L., J. Beringer, N. Nicholls, R.J. Hyndman, and N.J. Tapper. 2011. Quantifying the influence of local meteorology on air quality using generalized additive models. Atmospheric Environment 45(6): 1328-1336.

Peduzzi, P., B. Chatenoux, H. Dao, A. De Bono, C. Herold, J. Kossin, F. Mouton, and O. Nordbeck. 2012. Global trends in tropical cyclone risk. Nature Climate Change 2(4): 289-294.

Shen, J., Z. Feng, G. Zeng, and B.P. Zhu. 2009. Risk factors for injury during Typhoon Saomei. Epidemiology 20(6): 892-895.

Shi, P., T. Ye, Y. Wang, T. Zhou, W. Xu, J. Du, J. Wang, N. Li, et al. 2020. Disaster risk science: A geographical perspective and a research framework. International Journal of Disaster Risk Science 11(4): 426-440.

Smyth, C.G., and S.A. Royle. 2000. Urban landslide hazards: incidence and causative factors in Niteroi, Rio de Janeiro State, Brazil. Applied Geography 20(2): 95-117.

Syvitski, J.P.M., A.J. Kettner, I. Overeem, E.W.H. Hutton, M.T. Hannon, G.R. Brakenridge, J. Day, C. Vörösmarty, et al. 2009. Sinking deltas due to human activities. Nature Geoscience 2(10): 681-686.

Tian, B., W. Wu, Z. Yang, and Y. Zhou. 2016. Drivers, trends, and potential impacts of long-term coastal reclamation in China from 1985 to 2010. Estuarine, Coastal and Shelf Science 170: 83-90.

Vrijling, J.K., W. Vanhengel, and R.J. Houben. 1995. A framework for risk-evaluation. Journal of Hazardous Materials 43(3): 245-261.

Wang, J.F., and C.D. Xu. 2017. Geodetector: Principle and prospective. Acta Geographica Sinica 72(1): 116-134.

Wang, J.F., X.H. Li, G. Christakos, Y.L. Liao, T. Zhang, X. Gu, and X.Y. Zheng. 2010. Geographical detectors-based health risk assessment and its application in the neural tube defects study of the Heshun region, China. International Journal of Geographical Information Science 24(1): 107-127.

Wang, J.F., T.L. Zhang, and B.J. Fu. 2016. A measure of spatial stratified heterogeneity. Ecological Indicators 67: 250-256.

Xu, L., Y. He, W. Huang, and S. Cui. 2016. A multi-dimensional integrated approach to assess flood risks on a coastal city, induced by sea-level rise and storm tides. Environmental Research Letters 11(1): Article 014001.

Xu, X., S. Peng, X. Yang, H. Xu, D.Q. Tong, D. Wang, Y. Guo, J.C.L. Chan, et al. 2013. Does warmer China land attract more super typhoons? Scientific Reports 3: Article 1522.

Yan, Q., T. Wei, R.L. Korty, J.P. Kossin, Z. Zhang, and H. Wang. 2016. Enhanced intensity of global tropical cyclones during the mid-Pliocene warm period. Proceedings of the National Academy of Sciences of the United States of America 113(46): 12963-12967.

Yang, D., X. Wang, J. Xu, C. Xu, D. Lu, C. Ye, Z. Wang, L. Bai, et al. 2018. Quantifying the influence of natural and socioeconomic factors and their interactive impact on $\mathrm{PM}_{2.5}$ pollution in China. Environmental Pollution 241: 475-483. 
Yang, L., J. Scheffran, H. Qin, and Q. You. 2015. Climate-related flood risks and urban responses in the Pearl River Delta, China. Regional Environmental Change 15(2): 379-391.

Ying, M., B. Chen, and G. Wu. 2011. Climate trends in tropical cyclone-induced wind and precipitation over mainland China. Geophysical Research Letters 38(2): Article L01702.

Yuan, S., S.M. Quiring, L. Zhu, Y. Huang, and J. Wang. 2020. Development of a typhoon power outage model in Guangdong, China. International Journal of Electrical Power \& Energy Systems 117: Article 105711.

Zhang, H., W.C. Ma, and X.R. Wang. 2008. Rapid urbanization and implications for flood risk management in hinterland of the Pearl River Delta, China: The Foshan study. Sensors 8(4): 2223-2239.
Zhang, Q., X. Gu, P. Shi, and V.P. Singh. 2017. Impact of tropical cyclones on flood risk in southeastern China: Spatial patterns, causes and implications. Global and Planetary Change 150: 81-93.

Zhang, Q., V.P. Singh, J. Li, and X. Chen. 2011a. Analysis of the periods of maximum consecutive wet days in China. Journal of Geophysical Research - Atmospheres 116(D23): Article 106.

Zhang, Q., W. Zhang, Y.D. Chen, and T. Jiang. 2011b. Flood, drought and typhoon disasters during the last half-century in the Guangdong province, China. Natural Hazards 57(2): 267-278.

Zhang, Q., W. Zhang, X. Lu, and Y.D. Chen. 2012. Landfalling tropical cyclones activities in the south China: intensifying or weakening? International Journal of Climatology 32(12): $1815-1824$. 